\title{
A CASE STUDY ON WEAR IN SOME BASIC PARTS OF TRACTOR ENGINES
}

\section{Younis, S. M. ${ }^{1}$, K. M. Abdelbary ${ }^{2}$ and N. A. Ahmad ${ }^{3}$ ABSTRACT}

The aim of recent research work is to investigate a case study on wear in some basic parts concentrated on the piston with oil-sealing rings, suction and exhaust valves and its guides. Some parts of the engine have been taken; piston engine and its rings (pressure and oil rings). Which was changed after 10 years at a rate of 3 hours of daily operation. A test (setting wear rate and friction coefficient) was performed for both the metal of the anti-slip rings oil as well as the inner part of the engine cylinder. The results proved that the rate of ring wear is greater than the rate of wear of the cylinder as well as the experiments showed the importance of lubrication in the engine since the results in the case of the sample after lubrication showed less wear rate than the dry sample without lubrication. The axial adjustment test was performed on a suction valve as well as an exhaust valve in the guide of each valve to determine the effect of deterioration after 10 years. The results showed that the exhaust valve was bent with $1^{\circ} 40^{\prime}$ and the suction valve at $2^{\circ} 20^{\prime}$. American Mechanical Engineering allows one degree in the case of rotary columns and three degrees of inclination in fixed columns as in the case of the sample.

Keywords: piston-cylinder tribosystem, wear rate, coefficient of friction, tractor engines, oil-sealing rings, cylinder wall, suction valve, exhaust valve, guides, Tribology.

\section{INTRODUCTION}

$\mathrm{W}$ ear, the hard surface damage, mostly including progressive loss of material, due to relative motion among that surface and a contacting element (Varenberg, 2013). In the course of wear particles analysis in lubricating oils, it is possible to determine what is wearing (metal kind), how it is wearing (concentration), and how excessive forces are affecting the wear (shape) (Tranter, 1989).

\footnotetext{
${ }^{1}$ Prof., Agric. Eng. Dept., Fac. of Agric., Cairo Univ., Giza, Egypt.

${ }^{2}$ Associate Prof., Agric. Eng. Dept., Fac. of Agric., Cairo Univ., Giza, Egypt.

${ }^{3}$ M. Sc. Student, Agric. Eng. Dept., Fac. of Agric., Cairo Univ., Giza, Egypt.
} 
Varenberg (2013) classified the distinguished wear were related to dry sliding, lubricated sliding, dry rolling, lubricated rolling, oscillating, solid particles motion and fluids motion.

Adhesive actions play a very significant role in surface friction, especially at the micro and nanoscale grade (Goryacheva et al., 2013 ; Goryacheva and Makhovskaya, 2017). It has determined experimentally and theoretically that at these levels, the contact characteristics and friction power consist on the mechanical characteristics of the interacting bodies, their surface energy, and surface roughness.

Fretting is the small rang pulse between two bodies in contact which occurs in a wide variety of mechanical methods. Though the capacity of fretting is less $(<300 \mu \mathrm{m})$, fretting can be source serious damage inclusive wear and fatigue (Jin et al., 2015). Surface structure and its properties affect effectively overall behavior of materials. Surface microstructure and material properties can play a significant function in failure control inclusive wear and corrosion (Saada et al., 2018). Friction is a major ingredient of lots of engineering operations, which in parts such as brakes or clutches where force transmission plays an important role. In other hand friction is an unwelcome occurrence, such as conduct in loss of accuracy in positioning control or the appearance of self-excited vibration (brake squeal). Therefore it is significant to be able to predict and control the dynamic friction force (Cabboi and Woodhouse, 2017).

In internal combustion engines elevated force of friction and wear damages are occurred in ring-liner contact at Top Dead Center nearby the top ring reversal point of cylinder liners (Anand et al., 2015). Both sliding surfaces depended on the forming of a defensive boundary film in the real area of contact by the anti-wear additives existent in engine oil lubricants.

Materials sophisticated for friction and wear reduction were usually known as tribomaterials (De Mello et al., 2017). These materials must firstly have mechanical and physical characteristics like strength, stiffness, fatigue life, thermal expansion, and damping, more the tribological properties. They added also, that in most common tribological systems, lubrications are effectively used to reduce friction and wear. Padilla et 
al., (2013) reported that sliding contact on metal to metal materials often leads plastic deformation underneath the wear surface those outcomes in surface roughness layers with microstructures that are extremely different from those of the bulk.

The sealing ring and cylinder wall are the main parts of diesel engines. The tribological performance of these tribomaterials has an essential effect on engine friction force loss, fuel consumption, harmful emissions, and effective gas sealing (Zhang et al., 2016), (20-30\% of missing engine mechanical power was due to the friction force loss in the ring/liner tribosystem). Clarify the wear generation rate of any engine from the pollution present in the oil is a way of indirectly monitoring the machinery condition, (Henneberg et al., 2015). They also, added that a sample for wear generation must have to take into account the lubrication system as well as the concentration of particles.

Jha et al., (2017) examined the friction and wear performance at 4 various normal loads of $5,10,15$, and $20 \mathrm{~N}$ in their study that synthesized $\mathrm{Cu}-4 \mathrm{wt} \% \mathrm{Ni}$ matrix composites. They concluded that wear technique for the $\mathrm{Cu} 4 \mathrm{Ni}$ matrix alloy was a combine of adhesive and oxidation wear and mostly abrasive for the composites containing hard TiC particles.

Holmberg and Erdemir (2017) presented the effect of friction and wear on energy exhaustion, economic costs, and $\mathrm{CO}_{2}$ emissions on universal scale. They concluded that new surface's feature, materials, and lubrication technologies for friction decreasing and wear protection in engines, machinery and other equipment worldwide, could potentially minimize energy losses because of friction and wear by $40 \%$ in the long range ( 15 years) and by $18 \%$ in the short range ( 8 years).

Friction and wear theory encountered in mechanical methods with moving components are directly linked to capacity, reliability and service life of the system, Khadem et al., (2017). So, reducing and controlling these phenomena to realize the desired system performance is fateful. Through more strategies developed for decreasing friction and wear, the coating has been successfully utilized in various engineering implementations to relieve tribological problems (Khadem et al., 2017). One of the features of coating is that they can be invented using an assortment of materials in 
different forms and structures to meet the requirements of the operating conditions. They added also, that through many kinds, a coating that is included of a combination of materials in the form of a multilayer have been gaining a lot of interest due to the added grade of freedom in tailoring the coating property.

Zhang et al., (2016) proposed a process involving the inverse method and the sequential quadratic programming algorithm to decrease the friction of a sealing ring whilst preserving a big oil film load carrying capability. Their approach considered the difference of mixed lubrication and variable viscosity of lubricant with temperature along the engine stroke, they showed that minimize of friction and maximize load carrying capacity of oil film may be equiponderant with each other when the degree of the polynomial is 2 and 5. Based on the interaction between the thermal impact and mechanical characteristics, an analytical type was established by Kennedy (1980), Gao et al., (2016)'s results showed that the volume of the connect hot spot was specified by the normal load and mechanical characteristics of the contacting materials was the temperature at the connect hot spots.

Tzanakis et al., (2013) reported that the predictable contact temperature values are significant to be quantified so as to predict failure mechanisms related to excessive thermal effects caused by sliding friction. Pearson et al., (2013) inspected the effect of temperature (between $24^{\circ} \mathrm{C}$ and $450^{\circ} \mathrm{C}$ ) on the wear rate and friction coefficient of a high force alloy steel (SuperCMV) in gross sliding fretting in the air.

The aim of recent research work is to investigate a case study on wear in some basic parts concentrated on the piston with oil-sealing rings, suction and exhaust valves and its guides and some of operating requirements of tractor engines mainly, fresh and used engine oil.

\section{MATERIAL AND METHODS}

Present research work was performed at Agricultural Experiment Station, Fac. of Agric., Cairo Univ. The purpose of the laboratory experiment was to answer the following questions: (1) why does wear happen? (2) how does it happen? And (3) where does it happen? In order to achieve clear and correct answers to these questions, a number of tests on some basic 
parts of the tractor's engine have been performed. To find out the condition of the tractor and find out the reasons behind the deteriorating event which led to the need for a comprehensive extensive overhaul part of the engine.

The tractor under investigation was Russian manufacturing with 90 HP, some parts of the engine were selected for testing purposes, which included: (1) the piston with oil-sealing rings and related cylinder wall, and (2) suction and exhaust valves and its guides. The laboratory tests were performed at Tribology, Equipment and Spare parts Center, Faculty of Engineering, Cairo University. Fig. (1) illustrates tested engine's parts under investigation.

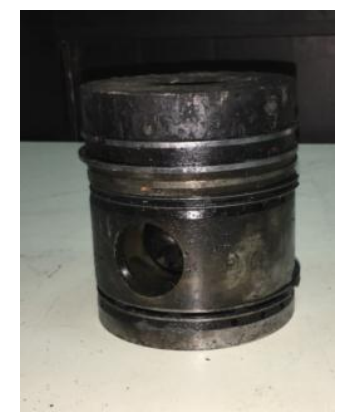

(a)

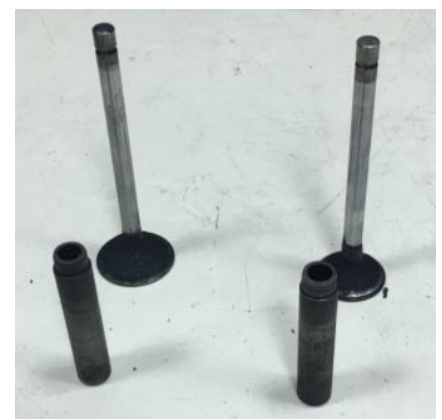

(b)

Fig. (1) Tested engine's parts under investigation, (a) the piston with oil-sealing rings, (b) suction and exhaust valves and its guides.

Determining the friction rate for both engine cylinder wall and sealing rings.

Wear and friction device plaint and patterns (Pin-on-Disc Wear tester), Figs 2 and 3, has been used to determine the friction rate for both engine cylinder wall and sealing rings. In a pin-on-disc wear tester, a pin is encumbered contra a flat rotative disc sample such that a rotating wear path is described by the instrument. The instrument can be used to estimate wear and friction characteristics of materials under sliding cases. Each disc or pin can be as a specimen, while the other as counter face. Pin can be used with several geometries. 
Pin-on-Disk wear testing is a process of describing the coefficient of friction, frictional force, and the wear rate between two materials and it is the most popular tribometer for examintion wear and the frictional behavior of a material under conditions of rolling, sliding, or a combination of both. To know the longitudinal distance in which the material went through the test conversion of rotational speed in the test for linear speed.

$$
L=V t=W R t
$$

Where:

$\boldsymbol{L} \quad$ longitudinal distance, $\mathrm{m}$.

$\boldsymbol{V} \quad$ linear speed, $\mathrm{m} \cdot \mathrm{s}^{-1}$.

$\boldsymbol{W}$ rotary speed, rpm.

$\boldsymbol{t}$ test time, sec.

$\boldsymbol{R} \quad$ radius of disc, $\mathrm{m}$.

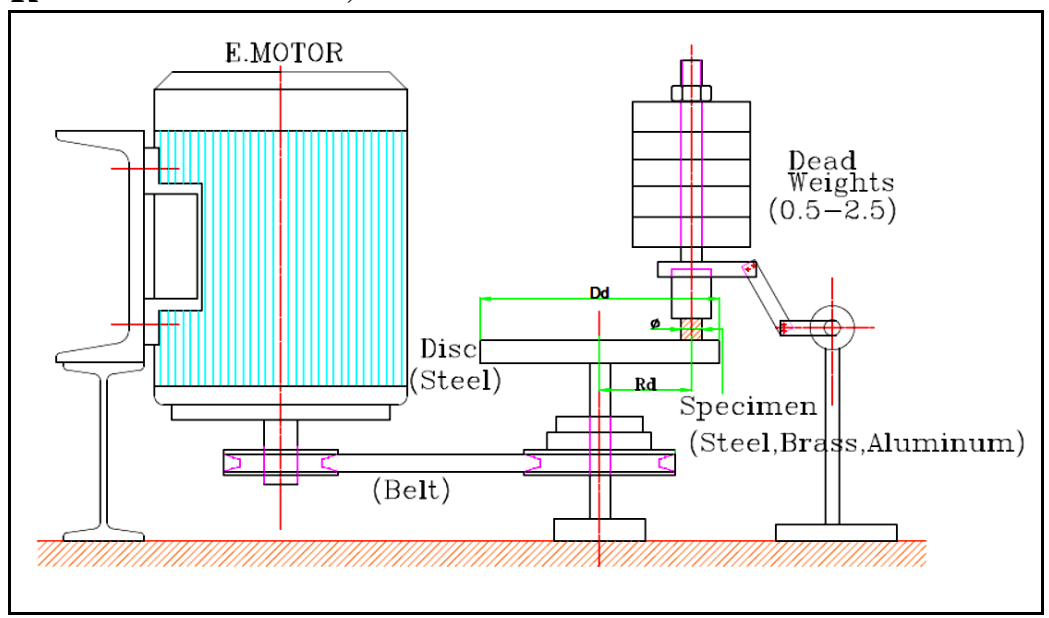

Fig. (2). Wear and friction device plaint and patterns (Pin-on-Disc tester).
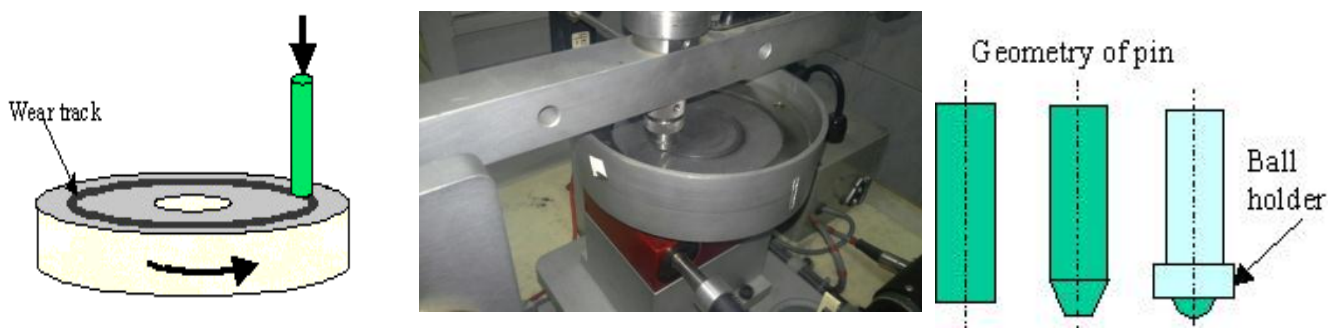

(a) Arrangement on sample

(b) Geometry of a pin

Fig. (3). Schematic of a pin-on-disc wear test and the arrangement of sample. 


\section{Test conditions}

Cylindrical test specimen diameter is $8 \mathrm{~mm}$ and $20 \mathrm{~mm}$ altitude was tested. Weight of $20 \mathrm{~N}$ is used as a normal force on the specimen. The loaded specimen remains contact with a rotated steel disc $(250 \mathrm{rpm})$ for ten minutes as a test time. The coefficient of friction value is read at each end of one minute to take the average of 10 readings. The weight of the specimen is measured before and after testing to determine the wear rate per unit distance. Test conditions were: (1) Disc diameter of $140 \mathrm{~mm}$, (2) Basic load of $20 \mathrm{~N}$, (3) Disc speed of $250 \mathrm{rpm}$ and (4) Test time of 10 min.

\section{Measuring of axial tuning of columns for suction and exhaust valves}

\section{and its guides.}

Profile gear tooth projector (Profile projector "PH3500") has been used to measure the axial tuning of columns for suction and exhaust valves and its guides. The principle of using this device depends on the use of the shadow to determine the angle of inclination from the basic horizontal level.

\section{RESULTS AND DISCUSSION}

\section{Determination of the wear rate for both engine cylinder wall and sealing rings.}

The friction force variations, the coefficient of friction are indicators of the wear beginning. In tribology, temperature appears as a significant factor indicative of the sharp wear appearance. The increase in body temperature can be detected by ways of thermography, a method well consolidated within the predictive maintenance. For tests on lubricated or non-lubricated surfaces, laboratory assessments are performed through tribometers, which can both find a tribological pair that is more resistant to friction failures and estimate the performance of particular lubricating oils.

Goryacheva et al., (2013) concluded that roughly 10-15\% of total energy generated in an internal combustion engine is lost to friction. In the piston-cylinder assembly, while the piston rings may account for more than $70 \%$ of the total friction-induced energy losses and the piston contribution to the friction of the system could also be substantial and 
should not be overlooked. Engine cylinder wall and sealing rings are tested under the weight of $20 \mathrm{~N}$ as a normal force and remained contact with a rotated steel disc for ten minutes as a test time. Friction coefficient measured data are illustrated in table (1) for cylinder wall and sealing rings.

Table (1). Wear Rate tested for Specimen of cylinder wall and sealing rings measured data.

\section{Specimen of cylinder wall}

\begin{tabular}{cc}
\hline Test with oil & Test without oil \\
$1.1 \times 10^{-4} \mathrm{gm} / \mathrm{m}$ & $1.3 \times 10^{-4} \mathrm{gm} / \mathrm{m}$ \\
\hline Specimen of sealing rings & \\
\hline Test with oil & Test without oil \\
$7.2 \times 10^{-4} \mathrm{gm} / \mathrm{m}$ & $7.7 \times 10^{-4} \mathrm{gm} / \mathrm{m}$ \\
\hline
\end{tabular}

Wear rate is defined as removal material's volume per unit displacement $\left(\mathrm{m}^{3} / \mathrm{m}\right)$, but in this test the weight of the sample was measured before and after the test and the wear rate was calculated for the weight of the sample. Wear rate due to friction in sealing rings was $7.7 \times 10^{-4} \mathrm{~g} / \mathrm{m}$ for dry test (without oil) and was $7.2 \times 10^{-4} \mathrm{~g} / \mathrm{m}$ for oiled test. It is clearly obvious that the oiled surfaces decrease the rate of wear by about $6.9 \%$ in rings material. Therefore, because lubrication works on reducing friction through the presence of a thin oil film it works to reduce the contact of the surface roughness.

The wear rate due to friction in the cylinder wall, has effected in the cylinder wall with weighs $20 \mathrm{~N}$ as a normal force, which is similar in real state to the weight of the piston almost inside the engine, Even the test is closest to the actual situation that occurs inside the engine during operation. The test was conducted in two cases of the sample the dry case (without oil) and the oiled case (with lubrication) which using the same type of oil that is used with this tractor during operation, which is used to lubricate the mechanical parts inside the engine (CO-OP Oil Super SJ 20W/50).

Wear rate due to friction in cylinder wall was $1.3 \times 10^{-4} \mathrm{~g} / \mathrm{m}$ for dry test (without oil) and was $1.1 \times 10^{-4} \mathrm{~g} / \mathrm{m}$ for oiled test. It is evidently noticeable 
that the oiled surfaces decrease the rate of wear by about $15.5 \%$ in cylinder wall material. This gives a clear indication of the amount of damage that can occur in the absence of oil lubrication or that the oil did not perform its role to the fullest or cause any change may cause a large wear rate and deterioration in the basic engine parts.

\section{Determine the coefficient of friction between both engine cylinder} wall and sealing rings $\&$ testing disc material.

Coefficient of friction between the cylinder wall material and testing disc materials is illustrated in Fig. (4). The coefficient of friction on cylinder wall was 0.418 for dry test and was 0.254 for oiled test. It is evidently clear that the oiled surfaces decrease the coefficient of friction by about $39 \%$ in cylinder wall material. So, such high values of coefficient of friction in the engine would oftentimes lead to unbearably high friction forces and frictional energy losses, as well as frictional heating. Hence, lubricants are used to decrease the frictional force between surfaces.

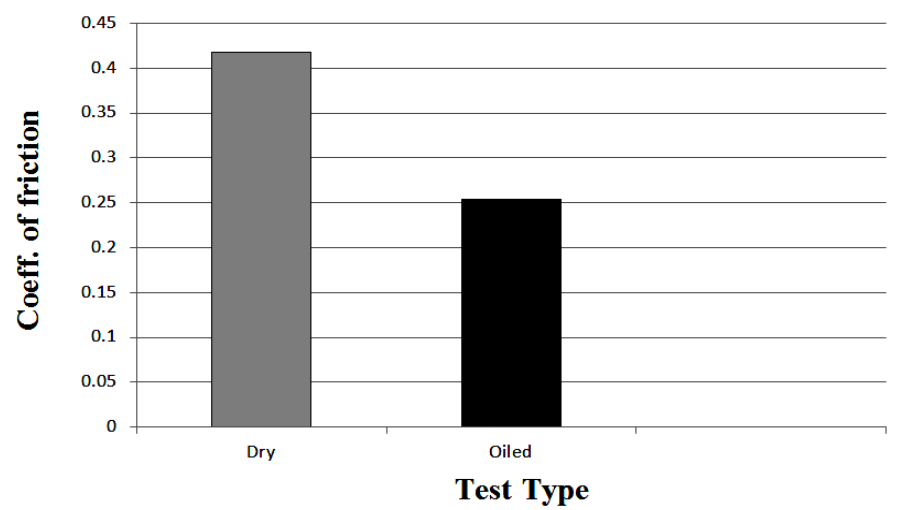

Fig. (4). Coefficient of friction between the cylinder wall material and testing disc materials.

Macian et al., (2016) reported that the internal engine friction can be as high as $50 \%$ of the mechanical losses in internal combustion engines. The objective of the test was to determine the state of the actual situation in the tractor engine to determination of the friction coefficient of the samples (without or using the same type of oil) used for lubrication in case of operation of the tractor to indicate the impact and effectiveness of oil during friction and also to estimate the state of deterioration that can 
occur in the absence of oil or failure of oil to perform its role as a layer of friction between the parts of the engine which leads to the deterioration and depreciation of the general parts of the engine, which reduces the maintenance intervals and increase the number of repairs and increase the cost of maintenance, which have a negatively affects the overall costs of operating the tractor.

Fig. (5) presents coefficient of friction between the sealing rings material and testing disc materials. The coefficient of friction for sealing rings was 0.447 for dry test and was 0.274 for oiled test. It is evidently noticeable that the oiled surfaces decrease the rate of wear by about $38 \%$ in sealing rings material.

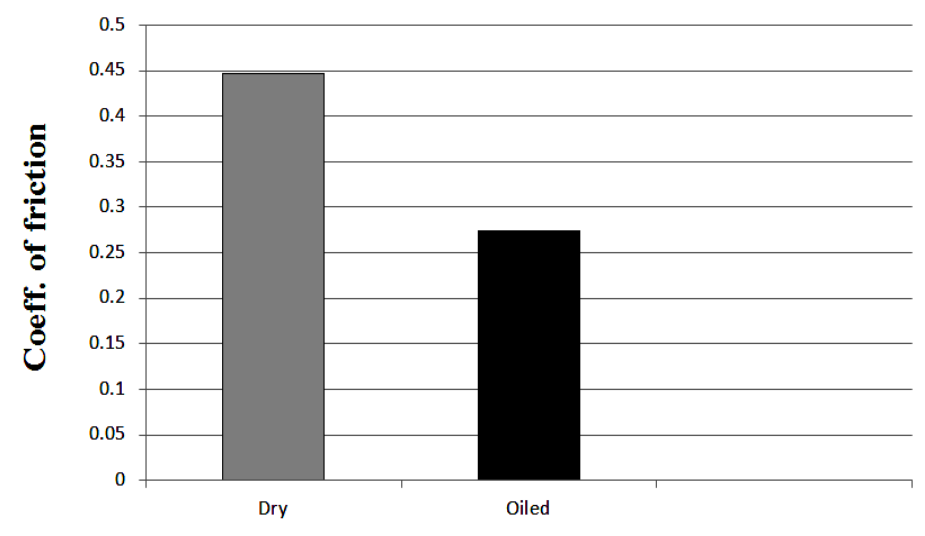

Test Type

\section{Fig. (5). Coefficient of friction between the sealing rings material and testing disc materials.}

All the pre-mentioned performed test ascertains the necessary for executing preventive maintenance program where the oil condition is detected by taking a sample of the test to estimate the expected deterioration of the oil before the deterioration occurs (Prediction) so as not to affect the properties of oil, Thus affecting its operational efficiency in the engine All this affects the friction within the engine and the friction coefficient of the mechanical parts. Thus increasing engine oil efficiency, the coefficient of friction decreases, leading to increased operational efficiency of the moving parts. Thus reducing the depreciation of these 
parts, this reduces the intervals of preventive maintenance. All this is due to the application of some predictive maintenance procedures along with preventive maintenance.

\section{Columns axial tuning measuring data for suction, exhaust valves and} its guides.

Measuring of axial tuning of columns for both suction and exhaust valves and its guides was performed using the shadow concept to determine the angle of inclination from the basic horizontal level, Fig (6). Result data showed that degree of inclination of the arm was $1^{\circ} 40^{\prime}$ for exhaust valve specimen and was $2^{\circ} 20^{\prime}$ for suction valve specimen.

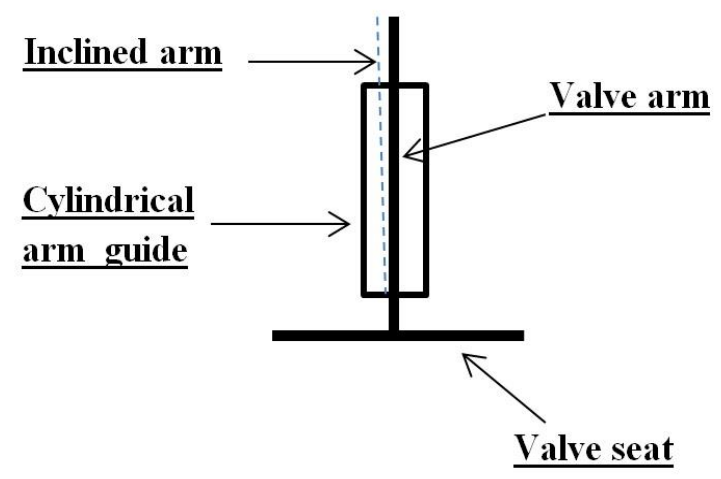

Fig. (6). Schematic of valve test.

These valves had accumulated working hours (10 years, 3600 days, about $11000 \mathrm{hrs}$ ). It is established according to ASME (American Society of Mechanical Engineering) code the allowable rotated columns permit to one degree. The allowable stationary columns (presented case) permit to three degrees. This means that the sample can be used for a longer period of time. This angle increases the friction between the arm and guide and as well as causes hearing pollution due to noise.

\section{CONCLUSION}

Solving the problem of enhancing the power efficiency and reliability of internal combustion engines is intimately associated with the improvement of the design of their tribosystems. The results proved that the rate of ring wear is greater than the rate of wear of the cylinder as well as the experiments showed the importance of lubrication in the engine 
since the results in the case of the sample after lubrication showed less wear rate than the dry sample without lubrication. The axial adjustment test was performed on a suction valve as well as an exhaust valve in the guide of each valve to determine the effect of deterioration after 10 years. The results showed that the exhaust valve was bent with $1^{\circ} 40^{\prime}$ and the suction valve at $2^{\circ} 20^{\prime}$. American Mechanical Engineering allows one degree in the case of rotary columns and three degrees of inclination in fixed columns as in the case of the sample.

\section{REFERENCES}

Anand, M., Hadfield, M., Viesca, J. L., Thomas, B., Hernández Battez, A., and Austen, S. (2015). Ionic liquids as tribological performance improving additive for in-service and used fullyformulated diesel engine lubricants. Wear, 334-335, 67-74.

Cabboi, A., and Woodhouse, J. (2017). Validation of a constitutive law for friction-induced vibration under different wear conditions. Wear, 396-397(August 2017), 107-125.

De Mello, J. D. B., Binder, C., Hammes, G., Binder, R., and Klein, A. N. (2017). Tribological behaviour of sintered iron based selflubricating composites. Friction, 5(3), 285-307.

Gao, S., Xue, W., Duan, D., and Li, S. (2016). Tribological behaviors of turbofan seal couples from friction heat perspective under highspeed rubbing condition. Friction, 4(2), 176-190.

Goryacheva, I. G., Morozov, A. V., Rozhdestvensky, Y. V., Gavrilov, K. V., and Doikin, A. A. (2013). Development of method for calculating and experimentally evaluating tribological parameters of piston-cylinder tribosystem of diesel engine. Journal of Friction and Wear, 34(5), 339-348.

Goryacheva, I., and Makhovskaya, Y. (2017). Combined effect of surface microgeometry and adhesion in normal and sliding contacts of elastic bodies. Friction, 5(3), 339-350.

Henneberg, M., Eriksen, R. L., Jørgensen, B., and Fich, J. (2015). A quasi-stationary approach to particle concentration and distribution in gear oil for wear mode estimation. Wear, 324-325, 140-146. 
Holmberg, K., and Erdemir, A. (2017). Influence of tribology on global energy consumption, costs and emissions. Friction, 5(3), 263-284.

Jha, P., Gautam, R. K., and Tyagi, R. (2017). Friction and wear behavior of $\mathrm{Cu}-4$ wt.\%Ni-TiC composites under dry sliding conditions. Friction, 5(4), 437-446.

Jin, X., Shipway, P. H., and Sun, W. (2015). The role of frictional power dissipation (as a function of frequency) and test temperature on contact temperature and the subsequent wear behaviour in a stainless steel contact in fretting. Wear, 330-331, 103-111.

Kennedy F E. (1980). Thermomechanical phenomena in high speed rubbing. Wear, An International Journal on the Science and Technology of Friction, Lubrication and Wear 59(1): 149-163. Elsevier.

Khadem, M., Penkov, O. V., Yang, H. K., and Kim, D. E. (2017). Tribology of multilayer coatings for wear reduction: A review. Friction, 5(3), 248-262.

Macián, V.; Tormos, B.; Ruiz, S. and Miró, G. (2016) Low viscosity engine oils: Study of wear effects and oil key parameters in a heavy duty engine fleet test. Tribol. Int., 94, 240-248; Elsevier.

Padilla, H. A., Boyce, B. L., Battaile, C. C., and Prasad, S. V. (2013). Frictional performance and near-surface evolution of nanocrystalline $\mathrm{Ni}-\mathrm{Fe}$ as governed by contact stress and sliding velocity. Wear, 297(1-2), 860-871.

Pearson, S. R., Shipway, P. H., Abere, J. O., and Hewitt, R. A. A. (2013). The effect of temperature on wear and friction of a high strength steel in fretting. Wear, 303(1-2), 622-631.

Saada, F. Ben, Antar, Z., Elleuch, K., Ponthiaux, P., and Gey, N. (2018). The effect of nanocrystallized surface on the tribocorrosion behavior of 304L stainless steel. Wear, 394395(October 2017), 71-79.

Tranter, J. (1989). The Fundamentals of, and the Application of Computers to, Condition Monitoring and Predictive Maintenance. COMADEM 89 Int., 372-377. 
Tzanakis, I., Conte, M., Hadfield, M., and Stolarski, T. A. (2013). Experimental and analytical thermal study of PTFE composite sliding against high carbon steel as a function of the surface roughness, sliding velocity and applied load. Wear, 303(1-2), 154-168.

Varenberg, M. (2013). Towards a unified classification of wear,. Friction 1 (4): 333-340.

Zhang, Z., Liu, J., and Xie, Y. (2016). Design approach for optimization of a piston ring profile considering mixed lubrication. Friction, 4(4), 335-346.

\section{الملخص العربيى \\ دراسة حالة عن التآكل الحادث فى بعض الأجزاء الأساسية لمحركات الجرارات}

سامى محمد يونس '، خالد محمد عبد البارى ' و نهاد عبد الرحمن احمدّ

الهذف من هذه البحث هو تحقيق دراسة حالة عن الاحتكالك في بعض الأجز اء الأساسية للمحرك

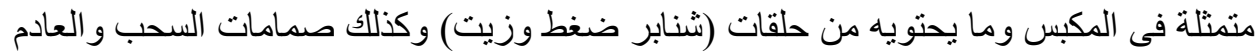

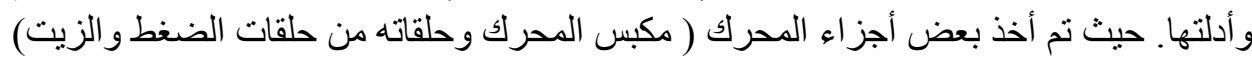

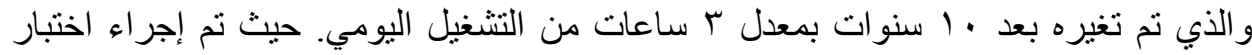

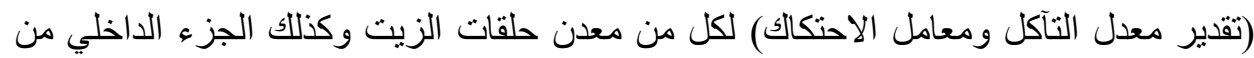

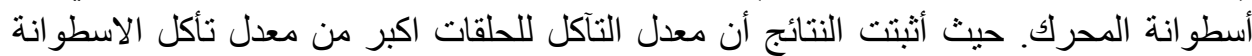

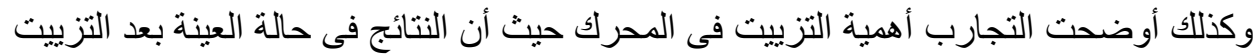

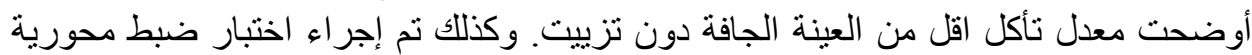

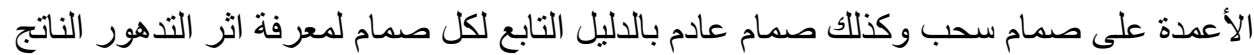

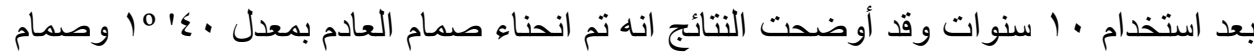

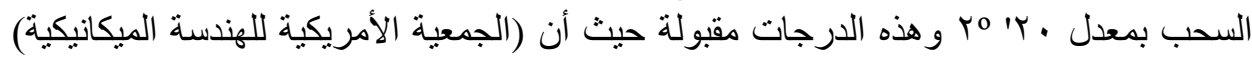

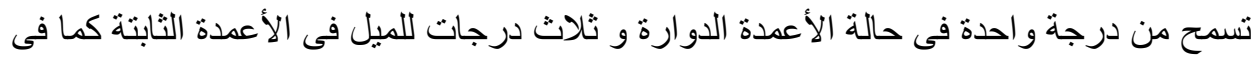

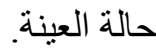

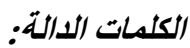
نظام مكبس ـ اسطوانة ، معدل الثآكل- معامل الاحتكاك ـ محركات الجرارات - حلقات التنزيبي- جدار

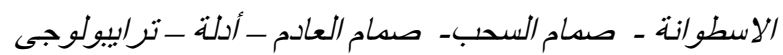

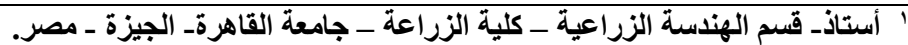

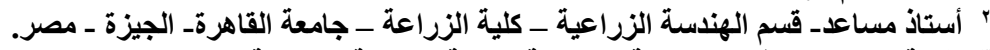

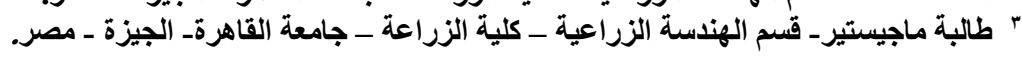

